\title{
Past and present attempts to control health service expenditure and its effects on National Health dentistry
}

\author{
N. M. Jessop, ' E. J. Kay, ${ }^{2}$ A. C. Mellor, ${ }^{3}$ J. G. Whittle, ${ }^{4}$ and A. Jenner, ${ }^{5}$
}

\begin{abstract}
Objective To examine the methods used by policy makers to try to reduce or limit expenditure within the National Health Service.

Method A chronological examination of cost related health care policy and its wider impact on society. Comparison of past developments in the NHS with new methods of health care organisation in the United Kingdom (UK). The experiences of two dental Total Purchasing Pilots are used to describe where the dental profession now stands in relation to current NHS developments.

Results The introduction of Primary Care Groups (PCGs) constitutes part of a continued effort by health care policy makers to control expenditure on health services. In the PCG system, as in Total Purchasing (TP), a group of primary care practitioners control a finite budget. These groups therefore must decide which health care services should be available to the population they represent. Inevitably such systems result in the rationing of health care, but the decisions are instigated by primary health care professionals rather than by government edict.

Conclusion Unless GDPs are allowed, willing and able, to participate in and influence the newly emerging Primary Care Groups and Trusts, dental services may once again be pushed to the fringe of NHS care provision. Without adequate representation, the value of dental care may not be recognised and PCGs may decide to make use of traditional dental resources, to fund other services.
\end{abstract}

\begin{abstract}
The introduction of the National Health Service (NHS) was 1 widely welcomed by the population of post-war Britain during a time of considerable deprivation. However, health care professionals were less enthusiastic about the proposed nationalisation. Representative organisations for the medical and dental professions voiced many objections to Aneurin Bevan's vision of health service provision and fought for a NHS which would be more financially favourable to the health care professionals. This is typified by the notable answer by Bevan when asked how he had gained hospital clinicians' support, whilst general medical practitioners still resisted the establishment of the NHS: 'I stuffed their mouths' with gold.'
\end{abstract}

\footnotetext{
$1^{*}$ Department of Oral Health and Development, ${ }^{2}$ Professor of Dental Health Service Research, ${ }^{3}$ Senior Lecturer in in Primary Dental Care, University Dental Hospital of Manchester, Higher Cambridge Street, Manchester M16 $6 \mathrm{FH},{ }^{4}$ Consultant in Dental Public Health, East Lancashire Health Authority, $31 / 33$ Kenyon Road, Lomeshaye Industrial Estate, Nelson BB9 5SZ, ${ }^{5}$ Consultant in Dental Public Health, South Cheshire Health Authority, 1829 Building, Countess of Chester Health Park, Liverpool Road, Chester CH2 1BQ

${ }^{*}$ Correspondence to: E. Kay

email:E.Kay@man.ac.uk

REFEREED PAPER

Received 20.10.99; Accepted 03.04.00

(c) British Dental Journal 2000; 189: 617-619
}

After much argument and debate, all health care professionals took part in the new health service after negotiations had delivered 'acceptable' conditions of employment. Intriguingly the dental profession, primarily represented by the British Dental Association, were the last to capitulate to Bevan's policy. Yet the offer of a generous fee scale and the widely known fact that the government favoured the option of 'salaried dentists', persuaded dental practitioners to join in with the new arrangements for the provision of dental care.

After Bevan had successfully brought health care professionals into the fold of the NHS he stated that his job was to: 'give you all the facilities, resources and help I can, and then leave you alone as professional men and women to use your skill and judgement without hindrance. Let us try to develop that partnership from now.'

Taking Bevan at his word, health care professionals provided the care their patients demanded. Opticians prescribed vast quantities of spectacles, doctors received huge numbers of visits, pharmacists gave out drugs and dentists responded enthusiastically to the colossal boom in requests for dentures.

In the first few months of the establishment of the NHS, 8 million people ( $16 \%$ of the population) sought dental treatment and of these, one third were supplied with artificial teeth. ${ }^{3}$ Thus, given this huge demand, the cost of dental health care which was free at the point of delivery became untenable even during the early stages of the NHS. Bevan had predicted that demand on health services would reach a natural ceiling after the initial rush declined. That is, he had assumed that the nation would become 'healthier' after they had taken up the newly provided services. He did not take into account new technologies, services other than acute care and the chronic and progressive nature of many diseases. Thus, a response was required in order to halt the wildly increasing health service expenditure.

\section{Attempts to limit expenditure}

Pharmacy, dentistry and opthamology were the first services to be targeted for cost cutting measures. Charges were introduced for prescriptions, patients had to pay half of the cost of dentures and in 1951 a 'flat-rate' fee for treatment was introduced. The BDA claimed that the introduction of charges would be ' most damaging to the dental health of the nation. ${ }^{4}$ Health care policy makers did not dispute this, but examination (or 'check-up') charges had not been introduced, so they argued that preventive rather than curative measures were being encouraged.

Until the 1960s there were rigid restrictions on any further expansion of health services, although, due to the original lack of an efficient structure and poor organisation, many improvements to the NHS were possible without adding to the financial burden. Between 1948 and 1973 the NHS measured the level of resources consumed by hospitals. However, no one knew how or for what purpose these resources were being used, or to what benefit to the population. Although there was potential for cutting costs without removing or 
rationing services during the early decades of the NHS, public policy 'think-tanks' and political parties experimented with the idea of reducing expenditure on health care. National Health Dentistry was not isolated from such drives, and from an early stage the dental profession felt there was a government agenda to remove dental services from health service provision.

\section{Continued need to reduce NHS expenditure}

However, as the NHS evolved further, it became apparent that costs could not continue to be contained solely by improving the structure or organisation of the system. Therefore, during the late 1960s and early 1970s formulae were developed by Crossman and the Resource Allocation Working Party. These redistributed available resources more 'equitably', but still failed to halt increasing costs in the health service. Policy makers became increasingly aware that difficult decisions would need to be made to prevent the percentage of UK tax revenue required to support the NHS becoming unsustainable. $^{5}$

\section{Conservative government policy}

The election of the Conservative Government in 1979 brought radical change to the structure of the NHS. The Health Service Act of 1980 attempted to make the system more efficient and effective by increasing accountability. District Health Authorities (DHAs) were instructed to outline plans and targets for their respective Regional Health Authorities. Yet again, this attempt to manage health care spending was less successful than was anticipated. Although DHAs had to state and justify their service plans, RHAs could: '... within reason, agree to tolerate some overspending if it can be off-set by other DHAs within the region' ${ }^{6}$

This placed RHAs in the position where they had to either penalise poorly performing DHAs and risk a public outcry, or support failing DHAs and thereby encourage inefficiency. In 1991 the Conservative Government again tried to encourage efficiency by devolving power to DHAs, RHAs and hospitals. The objective was to improve hospital service delivery and reduce costs by allowing those that wished to, to become 'Trusts'. This enabled hospital trusts to gain self-determination and therefore structure their organisation in a way they believed to be the most effective. Along with this increased autonomy for hospital providers was an increased potential for RHAs and DHAs to intervene should a Trust offer a poor level of service, or persistently overspend.?

The movement of the NHS from a hierarchical structure dictated to by central government, to an organisation which allowed a degree of local responsiveness had positive benefits. However, decisions relating to the rationing of health care and closure of facilities remained difficult to address. Public and professional opinion was often very strong and controversial decisions such as closure of local 'cottage' hospital were met with considerable opposition. Health authorities needed to justify the allocation of available resources and possible hospital closures to the populations they served. This task was difficult to achieve as public opposition was often encouraged by both primary and secondary care professionals.

\section{The introduction of fundholding}

Health care policy makers became increasingly aware that if a successful control mechanism for NHS expenditure was to be achieved, the active participation of health care professionals, particularly medical practitioners, was essential. This realisation led to the introduction of 'fundholding' in 1991. This system relied on the assumption that those in the 'front-line' of health care are best placed managing service provision. Under the fundholding system it was hoped that medical practitioners would be able to control effectively which services were 'bought' for their practice population. Also by allocating medical practitioners a budget, it was expected by policy makers that GMPs would become fully aware of the costs associated with their clinical decisions. From the Government's point of view fundholding represented a system of accountability which would ensure that medical practitioners realised that the care they offered to patients had cost implications.

Fundholding not only offered a system of increased accountability in general practice, but also in secondary care provider units. As purchasers of a service GMPs were able to negotiate contracts, utilise the most efficient service providers and improve the quality of the service. Perhaps most importantly, fundholding made it essential that secondary care providers liaised with general practice, something which had not always occurred in the past.

However, the introduction of fundholding also had negative impacts on health care provision. The creation of an internal market' allowed GMPs to shop around for the cheapest or best services for their patients. This could destabilise secondary care providers, and adversely effect those patients not registered with a fundholding medical practice. The threat of a medical practice removing funding from a hospital provider often led to favourable 'prices' and improved services being offered to fundholding practices. Thus, fundholders could provide their patients with additional services which were not available to others. In contrast to this situation, some fundholders found themselves in a position with very little influence because their locality did not have a choice of providers. In these areas secondary care providers could prove obstructive to change and short of referring patients to alternative hospitals in a distant area, GMPs could do little.

\section{The emergence of total purchasing}

Public and professional pressure created the need for an alternative to fundholding. Total Purchasing (TP) was launched in April 1995 to fulfil this objective. In England and Scotland 53 sites were established. The system of TP allowed a group of GMPs to 'purchase' hospital and community health services from a budget devolved to them from health authorities. It was this full devolvement which distinguished total purchasing from fundholding. As with fundholding, this NHS development was designed to use medical practitioners as commissioners, and as such, 'gatekeepers' of secondary care budgets.

\section{Dental total purchasing pilots}

Total purchasing GMPs could potentially make decisions on the provision of secondary care dental services. They could restrict referral levels and place contracts with specific providers, thus effectively limiting the clinical freedom of GDPs to refer for treatment. Yet, of the $53 \mathrm{TP}$ sites not one included primary dental care representation. In response to concern raised by the dental profession in the NorthWest Region, the NHS Executive funded a two-year investigation in April 1996 to examine the suitability and outcome of involving GDPs in TP groups.

Dental representation was linked into two existing TP sites as a sub-group of the medical project. Each dental TP pilot had the same organisational structure which consisted of:

- A lead GDP to offer advice to project development and to represent colleagues in the locality

- A Consultant in Dental Public Health to offer epidemiological advice to GDP total purchasers and ensure that commissioning decisions adhered to the Health Authority's overall oral health strategy

- A lead GMP to act as a link between the medical and dental TP groups

- The TP project manager to offer advice on contracting and service decisions, as well as to ensure a co-ordinated approach between the medical and dental groups

A researcher took an active part in both dental pilots in order to inform each of them of progress in their counterpart site. The 
research fellow also evaluated whether the dental pilots had the ability, support and motivation to be successfully included in the total purchasing model of commissioning.

As part of the study the purchasing decisions of each group of TP dental practitioners were studied in order to assess their suitability for the localities' population. In both sites decisions on the provision of dental care services followed similar objectives.

\section{Quality of service}

Quality of service was an issue in each site. Communication between hospital providers and dental practitioners was the principal area which GDPs believed could be improved. Each dental TP group wanted to create a more seamless style of service delivery, as it was felt that a lack of communication between GDPs and hospital clinicians adversely affected patients. Common referral forms rather than 'ad hoc' letters were introduced in the hope that this would improve interaction between the two sectors. It also prevented GDPs from being unaware of secondary care interventions on their registered patients.

\section{Budgetary savings}

In common with fundholders, and medical total purchasers, TP dental practitioners also attempted to make reductions in service expenditure, thus adhering to Government objectives. There were several methods that were proposed to gain cost savings whilst maintaining and potentially improving current levels of service. The foremost of these was a decrease in the number of dental referrals to hospital providers. Several methods were discussed to facilitate this, but all relied upon co-operation between participating GDPs in the form of referral protocols. Treatments which could be performed in primary care were defined and the protocols suggested that these should not be referred to hospital providers. This would create potential cost savings to the dental TP site. The use of inter-practice referral was also discussed and agreed upon for some procedures, thereby preventing their referral to a secondary care provider, and potentially reducing spending on secondary care provision.

Referral patterns were monitored by both dental sites, as some hospital providers offered lower cost dental speciality services than others. The TP GDPs did not wish to compromise quality of service, but wanted to ensure whenever possible that the most efficient providers of a service were used.

A further idea was reduction in oral surgery outpatient attendance by using 'direct referrals'. Through the use of a new type of referral form hospital clinicians could assess the appropriateness of the GDPs referral and either accept it and place the patient on the waiting list, reject it and request to see the patient, or ask for further information. This system therefore not only reduced pre-operative outpatient appointments, but also the cost for hospital attendance which would be charged to the TP site.

\section{Usage of cost savings}

The two dental TP sites had similar views regarding the proposed usage of the funds which the above service changes released. Each group of dental practitioners wanted to purchase dental 'outreach clinics. These clinics would be staffed by hospital clinicians and located close to the population they were to be purchased for. In effect, services which were normally only available in a secondary care setting were to be moved to primary care.

The benefits of such services were seen as increased accessibility for the patient and it was also hoped that the outreach clinic would address the principle issues raised regarding quality of service. The clinics would be held locally at set times and therefore it was thought that this would improve communication between hospital clinicians and GDPs. In a similar way to fundholding, the purchasing function of the TP dental practitioners would encourage interaction between professionals in the primary and secondary care sectors.

\section{Outcomes}

In each dental TP site GDPs voluntarily sought to reduce expenditure for the same level of service to their population. This followed the trend set by medical practice led purchasing. However, despite achieving these savings, both dental total purchasing sites failed to establish outreach clinics in their localities. One site was unable to clearly define a budget for this purpose, whilst the other could not find a hospital clinician willing to provide the service.

Total purchasing sites were piloted in only 53 sites across England and Scotland. In contrast, newly emerging Primary Care Groups (PCGs) are being set up in every locality of England and all patients are allocated to one. Service provisions made by such groups should therefore prove to be more enforceable than was experienced by the dental TP sites. A primary care led NHS therefore looks likely to be effectively implemented. Total purchasing is the closest model of health service organisation to PCGs and thus the dental pilots offer important guidance as to the possible outcomes. If PCGs follow the trend set by fundholding and TP, they will look for methods of using resources as efficiently and effectively as possible, whilst maintaining the quality of service utilised.

In the TP sites dental practitioners were actively involved in decisions on service provision. This reassured them that any savings in expenditure achieved in dental services would be redirected to dental rather than medical specialities. Oral Health Advisory Groups (OHAGs) have been established to offer advice to PCGs. However, without direct dental representation on PCG committees, nonacute dental care may be viewed as unessential and a potential area for cost cutting. Thus, unless GDPs are allowed and willing to participate in PCGs dental services may suffer, and will almost certainly not be provided in the way which GDPs believe benefit patients the most.

1 Ed. Malek M, Vacanci P, Rasquinha J, Davey P. Managerial Issues in the Reformed NHS, p 2. West Sussex: John Wiley \& Sons Ltd, 1993.

2 Rivett,G. From Cradle to Grave, p 48. London: The King's Fund, 1998.

3 Webster,C. The National Health Service: A Political History, pp 48-49. Oxford: Oxford University Press, 1998.

4 Webster,C. The Health Services since the War (Vol. 1), pp 485. London: HMSO, 1988.

5 Rigden, M. Health Service Finance and Accounting, pp5-35. London: Heinman, 1983.

6 Rigden, M. Health Service Finance and Accounting, p 6. London: Heinman, 1983.

7 Ed. Malek M, Vacanci P, Rasquinha J, Davey P. Managerial Issues in the Reformed NHS, p 2. West Sussex: John Wiley \& Sons Ltd, 1993. 